\title{
A company-oriented model for the assessment of raw material supply risks, environmental impact and social implications
}

\author{
Christoph Kolotzek, Christoph Helbig, Andrea Thorenz*, Armin Reller, Axel Tuma
}

Resource Lab, University of Augsburg, Universitaetsstr. 16, 86159 Augsburg, Germany

\begin{abstract}
A B S T R A C T
Since manufacturers are the main drivers in the selection of the materials used in their products, they have a special responsibility for investigating the accompanying sustainability aspects. The recently increased attention they pay to these issues is motivated not only by a sense of social responsibility, but also by pressure from customers and competitors. In particular, the three dimensions of sustainability - based on the triple bottom line of economic, environmental and social criteria - are of growing importance for sustainable supply chain management. Raw materials and their supply chains are often at the focus of attention, since manufacturers may need to diversify them for their products. Appropriate assessment models then become essential. Although raw material assessments and raw material-focused decision support schemes have recently been applied more often in the corporate context, several aspects such as indicator selection, weighting or social assessment are rarely considered. As a result, a comprehensive, sustainability-oriented raw material assessment and decision support scheme in the corporate context is not available in the scientific literature. In the design of such a scheme, four questions arise: First, how should a corporate-oriented raw material assessment model be structured? Second, how can all three sustainability dimensions be taken into account? Third, how can the application of raw material assessments in a corporate-oriented decision-making process increase the sustainability level of a company? And fourth, does a methodically structured raw material assessment model have advantages over existing models? To answer these questions, we have developed a model which takes into account state-of-the-art sustainability assessments as well as recent developments in the field of criticality analysis, life cycle impact assessment (LCIA) and social life cycle assessment (SLCA). With partners from both academia and industry we identify relevant quantitative indicators for structuring the assessment model and for calculating corresponding indicator weightings, using the analytic hierarchy process (AHP). To demonstrate the applicability of the assessment model for decision support and its benefits for companies in identifying potential hotspots in raw material supply chains, we present a case study that includes decision support for selecting capacitor technologies. A sensitivity analysis demonstrates the robustness of the assessments. In short, this article presents a sustainability-oriented raw material assessment and decision support model and proposes how it should be applied in a corporate context.
\end{abstract}

\section{Introduction}

Manufacturing companies are the key actors in increasing resource efficiency and promoting sustainable production through appropriate material selection, product design or process engineering. Auxiliary materials and the components of preliminary products, can contain up to 60 different raw materials for a single

\footnotetext{
* Corresponding author

E-mail address: andrea.thorenz@mrm.uni-augsburg.de (A. Thorenz).
}

product (Graedel et al., 2015a). Manufacturers may therefore depend on many different supply chains, each of which might give rise to economic and operational disruptions due to shortages, environmental considerations or social aspects (Huy et al., 2013; U.S. Department of Energy (DOE), 2011). A company therefore needs to know which risks pertain in the supply chain, as seen from all sustainability perspectives and how these potential risks can be reduced (Fridgen et al., 2013). Companies are also motivated by pressure from customers or competitors to improve environmental and social aspects along their product supply chains. They are also 
held responsible for what happens along their supply chains (Ahi and Searcy, 2013; Pagell and Wu, 2009; Seuring and Müller, 2008). Due to this situation, companies turn to the concept of sustainable supply chain management (SSCM) (Carter and Rogers, 2008), which is based on the triple bottom line concept (Elkington, 1999; Crum et al., 2011). These authors conclude, amongst other things, that sustainability-oriented companies are expected to be economically more successful on a long-term perspective. Raw materials are also identified as an important parameter that can increase the sustainability rating of the company. This needs quantitative evaluation in addition to the already established stakeholder and process evaluation in the supply chain (Stindt, 2017). If the data availability is sufficient, raw material assessments are even valuable for assessing complex products such as cars (Henßler et al., 2016). Moreover, social aspects of raw material utilisation are often ignored when it comes to model development. In further research, modeling the interrelation among all three sustainability dimensions seems necessary (Pimentel et al., 2016; Seuring, 2013). Furthermore, raw material supply chains are rarely considered within the concept of SSCM (Sauer and Seuring, 2017). In this article, we therefore focus on a semi-quantitative assessment of raw material supply with respect to all three sustainability dimensions, thus allowing corporate decision makers to use raw material-specific information.

Relevant for this article on the assessment of raw materials are the methodologies of criticality assessment, life cycle impact assessment (LCIA) and social life cycle assessment (SLCA). LCIA and SLCA both assess processes during the life cycle of a raw material from an environmental or social perspective. Criticality assessments are generally static multi-criteria assessment models that evaluate raw materials according to selected indicator performances and can be integrated into the concepts of sustainable product design and sustainable procurement, which are two out of nine generic SSCM concepts for improving sustainability (Stindt, 2017). They give a first insight as to the potential hotspots at the beginning of supply chains and are characterized by good data availability ( European Commission, 2014; Graedel et al., 2015b). In order to promote sustainable decision support on raw materials for companies, an integrated assessment including economic, environmental and social dimensions is required. The calculation of the results also has to be understandable for corporate decision makers without unreasonable effort. The concept of criticality assessment can therefore be extended with the information gathered in LCIA and SCLA, if their specific applicability is ensured.

When it comes to decision support, the interpretation of indicators and corresponding weightings can be essential (Diakoulaki et al., 1995; Figueira and Roy, 2002; Yeh et al., 1999). The present article therefore investigates various research issues in this context. They may be formulated as four questions: For a criticality-based raw material assessment model on the corporate level ...

Q1 ... how should the indicators and the corresponding weightings be selected and assessed?

Q2 ... how should a separate social assessment dimension be structured?

Q3 ... how can a raw material assessment model as a companyoriented decision support system be used to select raw materials?

Q4 ... does the selection of indicators and of the corresponding weightings in the system elaborated here have advantages compared to previous schemes?

In particular, the process of raw material assessment $(\mathrm{Q} 1+\mathrm{Q} 2)$, assessment model applicability (Q3) and sensitivity analysis (Q4) need to be integrated into the corporate context, which would then increase the applicability of the model. Based on Buchholz (2014) and Tuma et al. (2014), a simplified guideline for the identification, assessment and handling of raw materials is shown in Fig. 1.

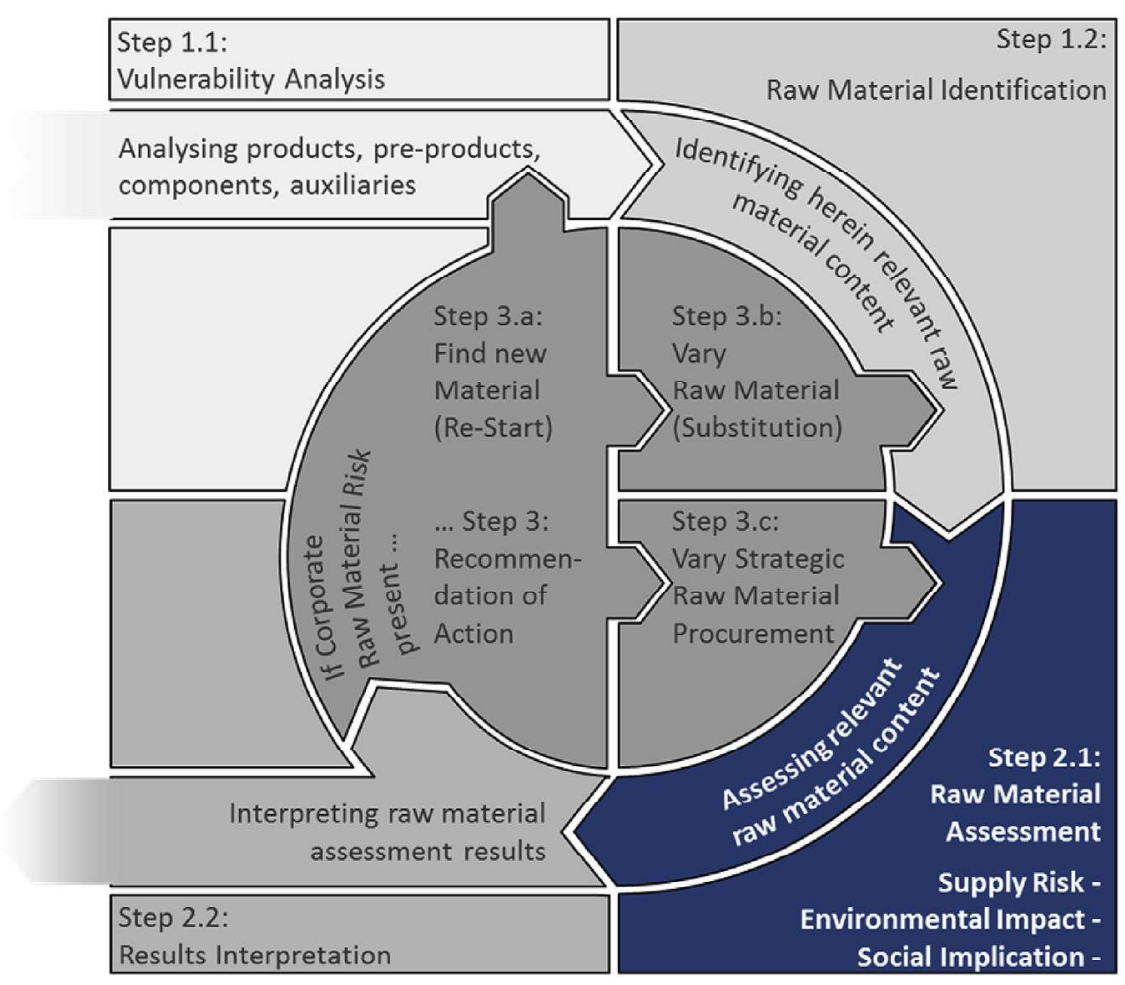

Fig. 1. Integration of raw material assessment into a simplified corporate guideline for the identification and appraisal of raw materials. 
The step "raw material assessment" is highlighted, since this is the focus of the present article.

In step 1 of the guideline, relevant raw materials are identified through vulnerability analysis (step 1.1) and content identification (step 1.2). In step 2, these relevant raw materials are evaluated with an assessment model (step 2.1) and interpreted from an individual company perspective (step 2.2) to identify critical raw materials. Step 3 closes the loop to re-start the process from the beginning if necessary (step 3.a) and delivers two fundamental alternatives to reduce potential risks from these critical raw materials through substitution (step 3.b) or procurement variation (step 3.c). The steps that follow vary, depending on the alternative chosen.

This article is organized as follows: the literature review section first introduces the concept of raw material criticality assessments, LCIA and SCLA and, second, identifies the need for more research. The materials and methods section presents the assessment model developed in the present work and describes the indicator selection and weighting (first and second questions). The applicability of the assessment model for decision support is demonstrated by a case study on the selection of the least critical technology used in electronic capacitors in the results section (third question), accompanied by a sensitivity analysis (fourth question). Subsequently, the implications of the results and the limitations of the presented assessment model are discussed. A conclusion summarizes the essential results in the article and points out promising areas for further research.

\section{Literature review and research gap}

In the literature, many sustainability-oriented studies focus on supply chain risks including transportation (Dekker et al., 2012), environmentally-oriented supplier selection (Govindan et al., 2015), or socially responsible sourcing (Zorzini et al., 2015). Raw materials are seldom targeted (Sauer and Seuring, 2017). From a company perspective, knowing the supply potential, geopolitical factors and intensity of competition is crucial for all raw materials that are relevant to the firm's product line (Graedel et al., 2012). Companies can also evaluate their raw materials with supply risk assessments within the concept of raw material criticality assessments. Raw material criticality is a heterogeneous field of research (Erdmann and Graedel, 2011), which has expanded over the past decade (Graedel and Reck, 2016). Criticality assessments usually consider two dimensions of interest - vulnerability and supply risk (Glöser et al., 2015) - sometimes extended by environmental impacts (Graedel et al., 2012) or by social implications (Bach et al., 2016). The dualism of supply risk and vulnerability in the economic dimension was established by the U.S. National Research Council (NRC) (U.S. National Research Council, 2008) and has been picked up by a EU study (European Commission, 2010; European Commission, 2014). Graedel et al. (2012) carried out their assessment on the company, national and global levels with customized indicator sets (Graedel et al., 2012). The methodology was then applied to a wide range of element groups (Graedel et al., 2015b; Harper et al., 2015a, 2015b; Nassar et al., 2012; Nassar et al., 2015; Nuss et al., 2014; Panousi et al., 2016).

Vulnerability on the raw material level is a part of raw material criticality assessments, where it describes the potential damage of a material-related restriction, whether due to supply disruption, environmental regulations or social implications; it does not describe the likelihood of such a restriction being implemented (Helbig et al., 2016b). These aspects should be considered by a company in the Step 1.1 or Step 1.2 of the guideline given in Fig. 1. Vulnerability is not a part of the raw material assessment in Step 2.1.
Applying global or national perspectives, which are frequently used in criticality assessments (Achzet and Helbig, 2013) in a corporate context, is often not advisable, as some indicators are of limited use for companies, such as 'risk of strategic use' (IW Consult, 2011), which focusses on the risk of countries using their raw materials as a political or strategic instrument. Some studies are available that assess raw materials from a corporate perspective (Duclos et al., 2008; Graedel et al., 2012; Bach et al., 2016). However, in criticality-based studies the processes of indicator selection and indicator weighting are discussed rarely from a scientific point of view (Graedel and Reck, 2016). As a consequence, most studies present an individual indicator set for raw material assessment, without mentioning in detail how this set was derived and which indicators were excluded for what reason. Not all indicators are suitable for a quantitative assessment, which is, however, preferred for decision support purposes. Even if a quantification is in principle possible, lack of required data for some indicators prevents the application to a large variety of raw materials and therefore limits the comparability of assessments. In this context the problem of indicator weighting is often neglected. However, customized weightings are essential for developing corporate strategies and achieving sustainability goals. As a consequence, the applicability of raw material assessments in a corporate context might be incomplete and important information from corporate decision makers is not used.

For the environmental part of criticality assessments, LCIA is vital: it is an environmental management method, standardized within the ISO norm 14040, which helps companies to select the most environmentally friendly products. Common LCIA methods differentiate three areas of protection (AoPs): human health, natural environment and natural resources (Finnveden et al., 2009). Human health (expressed by the ReCiPe method in disabilityadjusted life years, DALYs) is the endpoint category that accounts for the damage to the AoP human health caused by toxicity, climate change, ionizing radiation, ozone depletion, particulate matter formation or photochemical oxidant formation. Ecosystem quality is the endpoint category that accounts for the damage to natural environment (biodiversity) due to species extinction (usually expressed in lost species years) caused by land use changes, climate change, ecotoxicity, eutrophication or acidification. Natural resources considers the impacts of physical resource depletion. The transformation of LCIA data to environmental indicators for environmentally-extended criticality assessments has been demonstrated by Graedel et al. (2012) and can be adapted for company-specific assessments. Due to the non-transparency of raw material supply chains and the resulting data limitations, the application of complete life cycle assessments (Guinée et al., 2011) is hardly feasible for many raw materials (Curran, 2012), especially for small and medium sized enterprises (SMEs) (Kyngdon-McKay et al., 2015).

The fundamental SLCA publications date back to 2006 (Dreyer et al., 2006; Weidema, 2006). A major increase in published research followed, which has increased the extent and heterogeneity of the field (Jørgensen et al., 2008; Parent et al., 2010; Wu et al., 2014). The 2009 United Nations Environment Programme guidelines for the SCLA of products encourage the improvement of social conditions for all participants along the product life cycle (UNEP/SETAC, 2009). Five stakeholder categories (consumers, local community, society, value chain actors, and workers), the corresponding subcategories and the inventory indicators are all part of a hierarchical assessment scheme (Benoît et al., 2010). Due to the complexity and non-transparency of supply chains, data collection is a difficult task, particularly for social aspects (Jørgensen et al., 2009; Lehmann et al., 2013; Parent et al., 2013) and for SMEs (Kyngdon-McKay et al., 2015; Smith and Barling, 2014). Specific 
supplier information is decisive for assessing reliably social conditions in the company's supply chain. Social circumstances are strongly affected by individual participants (Jørgensen et al., 2012); thus, the SLCAs for two identical products can be different (Kruse et al., 2009). However, the assessment of social hotspots within a supply chain on the country or sector level serves as a first insight (Lehmann et al., 2013). Ekener-Petersen and Finnveden (2013) conducted a complex country-level case study that evaluated social hotspots within the supply chain of a laptop computer. The Social Hotspots Database (SHDB) helps identifying hotspots on the country or sector level (Benoît Norris, 2014; Benoit-Norris et al., 2012), and its applicability has been demonstrated in several case studies (Norris et al., 2014). There is need for more research in the social dimension in order to select applicable and quantifiable indicators from the indicator candidates for all stakeholder categories.

\section{Material and methods: assessment model}

The structure of the present assessment model is based on information from the literature search, expert questionnaires, expert workshops and the analytic hierarchy process (AHP). The structure of the assessment model is illustrated in Fig. 2 which also shows the corresponding weightings. All three assessment dimensions consist of general risk criteria, which contain corresponding indicators (supply risk, environmental dimension) or sub-criteria (social dimension, which may contain multiple indicators). For reasons of simplicity, both indicators and sub-criteria are from hereon termed 'indicators'. Detailed calculations are presented in the supplementary material.

Three main goals are set for the assessment model: (1) the three dimensions supply risk, environmental impacts and social implication are considered by using relevant indicators from a company perspective; (2) all the selected indicators and their individual weightings are applicable for companies; and (3) all the selected indicators are (semi-)quantitative to provide unambiguous and readily understandable decision support information. In chapter 4 , the assessment model is used in a case study to investigate three different capacitor technologies. The three capacitors present a straightforward example, as they are to be found in almost every piece of electronic circuitry. In the case study, each capacitor represents one specific raw material. The robustness of the results is tested by a sensitivity analysis, where both the effects of excluding single indicators and of different indicator weightings are considered.

Meaningful indicator weightings can be essential when using raw material assessments for decision support. These weightings can be achieved using an AHP (Saaty, 1990; Hossaini et al., 2014; Hosseinijou et al., 2014), a well-established method for solving multi-criteria decision problems based on pairwise comparisons of evaluation criteria (Saaty and Varga, 1994). Companies and experts from different fields of research were asked to participate in an AHP to determine the weightings of all indicators in the supply risk and social dimensions (see Fig. 2). Detailed information on the participation of these experts, the industrial sector to which they belong or their field of research is listed in a table in the supplementary material. Because the ReCiPe methodology used already includes a weighting for human health and ecosystem quality, an individual weighting is unnecessary for the environmental dimension. Excerpts from the questionnaires and additional calculations including the AHP methodology can be found in the supplementary material.

The experts were first asked to weight the general risk criteria in each dimension and to subsequently weight the indicators within each risk criterion. The average of the weightings from all experts was then used as the overall weighting of the supply risk and social indicators. The consistency ratios of all the comparison matrices for the AHP were well below the recommended threshold of 0.1 , so that the resulting weightings can be utilized. The three dimensions in the assessment model are not aggregated, which emphasizes the importance of evaluating every dimension separately.

\subsection{Supply risk assessment}

A final set of eleven indicators for the supply risk dimension was selected after (i) a detailed literature analysis on how frequently indicators have been used in different studies was conducted; (ii) experts from different fields of research and companies rated the importance of single indicators; and (iii) the applicability of single indicators was identified from a company perspective. Additional information is presented in the supplementary material. This indicator set for raw material supply risk assessment was already successfully applied to evaluate and compare the supply risks associated with thin-film photovoltaic cells and lithium-ion batteries (Helbig et al., 2016a, 2018).

(i) The supply risk dimension for the present raw material assessment is based on an extensive literature review. Scientific articles and project reports from both private and state-run institute projects have been evaluated in a wide range of corresponding research fields, such as environmental sciences, ecology, geology, material science, engineering and business administration (Achzet and Helbig, 2013; Tuma et al., 2014). Criticality assessments that quantify the supply risk of raw materials have been evaluated with regard to their selected indicators. From 24 different studies we categorized 28 different supply risk indicators according to (Achzet and Helbig, 2013).

(ii) In a questionnaire, experts from academia and industry rated the 28 identified supply risk indicators according to their importance on a scale from 1 (most important) to 6 (not important). Indicators with an average rating of 4.0 or worse are considered to be not relevant for the construction of the supply risk dimension. This was known to the participants, before they filled in the questionnaire. Here, some aspects are worthy of attention: Two experts from industry did not rate any indicator lower than 4 , thus considering all 28 indicators to be relevant. On the contrary, other experts excluded up to eight indicators with a rating of 5 or 6 . The static reach of the resources and price volatility of raw materials were nearly excluded by the experts from academia due to average ratings of 3.3 and 3.5, respectively, but were considered of higher importance by industry experts. In general, industry experts, compared to academia experts, were rather cautious about excluding indicators. This can derive from the fact that industry experts may not be familiar with the different alternatives for raw material assessment and are therefore perhaps strongly influenced by personal experience. One expert from industry, for instance, rated the indicator "extreme natural events" as most important, because the tsunami in March 2011 near the Japanese coast caused bottlenecks in the supply chain of his company. On the other hand, some experts thought that this indicator was only of minor, or no, relevance. Only two experts from industry made suggestions for additional indicators. The first was to assess the extent of knowhow on separation or refinery processes. The second was to assess the price volatility of competing companies. Unfortunately, it is difficult to express these two suggestions in terms of quantitative indicators.

(iii) Indicators with an average rating of 4.0 or better are then evaluated if they fit the expectations for the assessment model. Non-quantitative indicators such as extreme natural events, production capacity inertia and risk of strategic use, which partly rely 


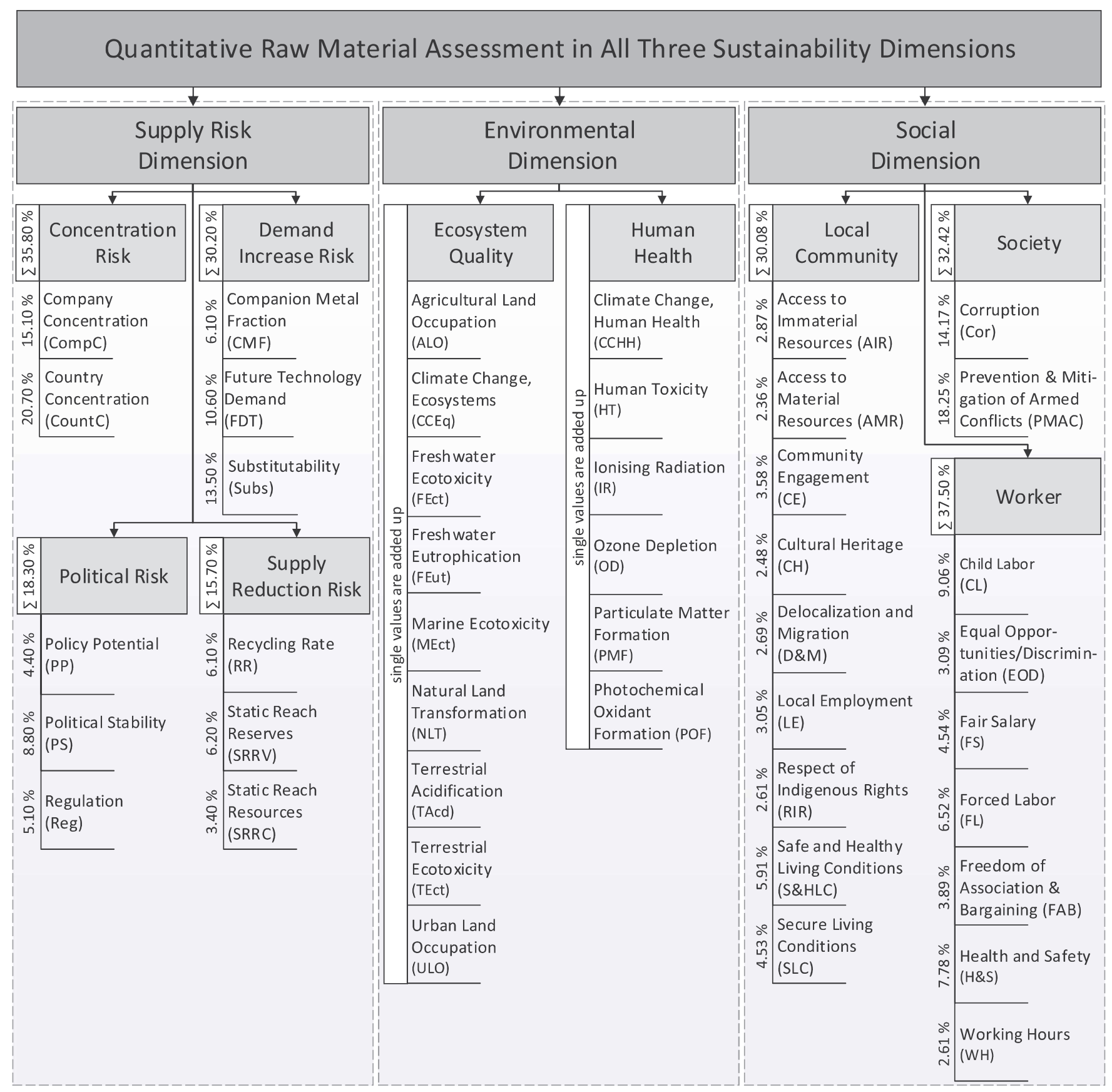

Fig. 2. Structure of the quantitative assessment model. The corresponding weighting is given next to each criterion.

on expert estimations, are therefore excluded. Some indicators like market balance and stock keeping, which rely on excessive data to be calculated, are excluded, too, because their applicability with respect to several raw materials is lacking. Other indicators such as commodity price volatility and environmental constraints are excluded. The reason for this is that they are already considered separately by most companies, or they focus on non-corporate perspectives or are already considered in the environmental assessment dimension. No indicator was excluded due to the frequency it was used in literature. However, for numerous raw materials, the findings present a positive correlation between frequency of use of an indicator and its applicability due to data availability. Table 1 summarizes the results of the supply risk indicator selection process.

An expert workshop was conducted to set up the assessment model, categorizing the eleven remaining indicators according to four main criteria: concentration risk, demand increase risk, political risk and supply reduction risk (Mason et al., 2011). Concentration risk addresses the concentration of critical raw material production at the country and company levels. Demand increase risk covers estimations of the fraction of companion metal, the demand for a raw material for future technologies and its substitutability. Political risk addresses the political stability of the producing countries, the ability to implement new mining 
Table 1

Summary of the results from the supply risk indicator selection process.

\begin{tabular}{|c|c|c|c|}
\hline Indicator & Used in literature & Included $(\checkmark)$ or excluded $(-)$ & Reason for exclusion \\
\hline Abiotic Depletion Potential & 1 & - & $\mathrm{C} 1$ \\
\hline Abundance in Earth's Crust & 2 & - & $\mathrm{C} 1$ \\
\hline Climate Change Vulnerability & 1 & - & $\mathrm{C} 1, \mathrm{C} 2$ \\
\hline Commodity Price Volatility & 5 & - & $\mathrm{I} 1$ \\
\hline Companion Metal Fraction & 10 & $\checkmark$ & - \\
\hline Company Concentration & 9 & $\checkmark$ & - \\
\hline Country Concentration & 19 & $\checkmark$ & - \\
\hline Country Risk Policy Potential & 3 & $\checkmark$ & - \\
\hline Country Risk Political Stability & 15 & $\checkmark$ & - \\
\hline Country Risk Regulation & 3 & $\checkmark$ & - \\
\hline Environmental Constraints & 2 & - & $\mathrm{I} 2$ \\
\hline Exploration Budget & 1 & - & $\mathrm{C} 1, \mathrm{C} 2$ \\
\hline Extreme Natural Events & 1 & - & $\mathrm{C} 2$, non-quantitative \\
\hline Future Demand Technology & 11 & $\checkmark$ & - \\
\hline Future Market Capacity & 1 & - & $\mathrm{C} 2$, data availability \\
\hline Import Dependency & 3 & - & $\mathrm{C} 2$, country-oriented \\
\hline Market Balance & 1 & - & $\mathrm{C} 2$, data availability \\
\hline Mining Investment & 1 & - & $\mathrm{C} 2$, data availability \\
\hline Production Capacity Inertia & 1 & - & $\mathrm{C} 2$, non-quantitative \\
\hline Production Capacity Utilization & 1 & - & $\mathrm{C} 2$, data availability \\
\hline Recycling Rate & 10 & $\checkmark$ & - \\
\hline Reserves Concentration & 7 & - & I3 \\
\hline Risk of Strategic Use & 1 & - & $\mathrm{C} 2$, non-quantitative \\
\hline Static Reach Reserves & 10 & $\checkmark$ & - \\
\hline Static Reach Resources & 3 & $\checkmark$ & - \\
\hline Stock Keeping & 2 & - & $\mathrm{C} 2$, data availability \\
\hline Substitutability & 8 & $\checkmark$ & - \\
\hline Trade Restrictions & 4 & - & 14 \\
\hline
\end{tabular}

Criterion C1: Average rating not better than 4.0.

Criterion C2: Not corporate-oriented, non-quantitative or not applicable for numerous raw materials due to data availability

Individual I1: Mainly monitored separately by companies.

Individual I2: Included within the Environmental Dimension.

Individual I3: Subordinated impacts to remaining concentration indicators.

Individual I4: Similar to the indicator Country Risk Regulation.

projects and potential legislative restrictions. Supply reduction risk is determined by the reserve-to-production ratio, the resources-to-production ratio and the worldwide end-of-life recycling rate.

\subsection{Environmental impact assessment}

To assess the raw material environmental dimension in the field of criticality analysis, only the two AoPs "ecosystem quality" and "human health" are well suited (Graedel et al., 2012). The AoP "natural resources" is taken up here in the supply risk assessment, not in the environmental impacts. Other raw material evaluations that have used the Environmental Performance Index (Hsu et al., 2014) instead of LCIA methods also use the two AoPs "ecosystem quality" and "human health" (European Commission, 2010; Roelich et al., 2014). The LCIA method 'ReCiPe' is one of several methods in this field and has been suggested as an interim solution for impact assessment (European Commission, 2011), first assesses impact categories (midpoints) based on life cycle inventories (LCIs) and uses normalization and weighting factors to aggregate these values into damage categories (endpoints), such as "human health" and "ecosystem quality" (Goedkoop et al., 2013). These factors imply a trade-off between environmental damage categories and depend on the selected regional scope and time horizon (Goedkoop et al., 2013).

The overall LCIA endpoint results are additive. The environmental impact of a product can therefore be estimated by adding up the selected raw material contents weighted according to their masses. Regularly updated and extended LCI databases, such as "ecoinvent", can help the company to collect data (ecoinvent Centre, 2010). Ready-to-use impact assessments regarding the damage caused by most raw materials to human health and ecosystem quality are based on the upstream supply chain impacts.

\subsection{Social assessment}

The social dimension is derived from the research field of SLCA (UNEP/SETAC, 2009), since quantitative raw material assessments for the social dimension in the field of criticality analysis are rarely available. Due to data availability issues, the social assessment presented in this article focuses on social hotspots on the country level or on the sector level per country. Five stakeholder categories, 31 corresponding subcategories and several more inventory indicators are proposed in the UNEP's guideline for social life cycle assessment (UNEP/SETAC, 2009) and the corresponding methodological sheets (UNEP/SETAC, 2013). The consumer category was excluded for the construction of the social dimension in this article, as the assessment model developed here focuses on the resource extraction and upstream supply chain, and no subcriteria from the consumer category (consumer privacy, end of life responsibility, feedback mechanism, health and safety, transparency) are relevant to target this process (Ekener-Petersen and Finnveden, 2013). The value chain actor category was also excluded due to a lack of suitable quantitative and applicable inventory indicators with regard to the scope of the assessment model. Generic inventory indicators are unavailable for the subcriterion supplier relationships (UNEP/SETAC, 2013). For the 
Table 2

Summary of the results from the social dimension indicator selection process.

\begin{tabular}{|c|c|c|c|}
\hline Stakeholder & Indicator & Included $(\checkmark)$ or excluded $(-)$ & Reason for exclusion \\
\hline \multirow[t]{5}{*}{ Consumer } & Consumer privacy & - & (1) \\
\hline & End of life responsibility & - & (1) \\
\hline & Feedback mechanism & - & (1) \\
\hline & Health and safety & - & (1) \\
\hline & Transparency & - & (1) \\
\hline \multirow[t]{9}{*}{ Local Community } & Access to immaterial resources & $\checkmark$ & - \\
\hline & Access to material resources & $\checkmark$ & - \\
\hline & Community engagement & $\checkmark$ & - \\
\hline & Cultural heritage & $\checkmark$ & - \\
\hline & Delocalization and migration & $\checkmark$ & - \\
\hline & Local employment & $\checkmark$ & - \\
\hline & Respect of indigenous rights & $\checkmark$ & - \\
\hline & Safe and Healthy living conditions & $\checkmark$ & - \\
\hline & Secure living conditions & $\checkmark$ & - \\
\hline \multirow[t]{5}{*}{ Society } & Contribution to economic development & - & (2) \\
\hline & Corruption & $\checkmark$ & - \\
\hline & Prevention and mitigation of armed conflicts & $\checkmark$ & - \\
\hline & Public commitments to sustainability issues & - & $(2)$ \\
\hline & Technology development & - & (3) \\
\hline \multirow[t]{4}{*}{ Value Chain Actors } & Fair competition & - & (2) \\
\hline & Promoting social responsibility & - & (2) \\
\hline & Respect of intellectual property rights & - & (2) \\
\hline & Supplier relationships & - & (4) \\
\hline \multirow[t]{8}{*}{ Worker } & Child labor & $\checkmark$ & - \\
\hline & Equal opportunities/discrimination & $\checkmark$ & - \\
\hline & Fair salary & $\checkmark$ & - \\
\hline & Forced labor & $\checkmark$ & - \\
\hline & Freedom of association and collective bargaining & $\checkmark$ & - \\
\hline & Health and safety & $\checkmark$ & - \\
\hline & Social benefits/social security & - & (2) \\
\hline & Working Hours & $\checkmark$ & - \\
\hline
\end{tabular}

(1) Not relevant concerning the raw material extraction process (Ekener-Petersen and Finnveden, 2013).

(2) ata non-availability and data non-specific impacts interpretation concerning goal and scope of the assessment model.

(3) Non-quantitative (UNEP/SETAC, 2013).

(4) No generic inventory indicators available (UNEP/SETAC, 2013).

remaining three sub-criteria fair competition, namely, promoting social responsibility and respect of intellectual property rights, the available data sources for relevant inventory indicators are qualitative and are not applicable for various raw materials due to data gaps on the country level. Assessing raw materials according to their producing countries is therefore not possible for many raw materials. For the same reason the three sub-criteria "social benefits/social security" (stakeholder worker), "contribution to economic development" and "public commitments to sustainability issues" (both stakeholder society) are excluded. The subcriterion "technology development" (stakeholder society) is excluded as only a qualitative assessment is possible (UNEP/ SETAC, 2013). Consequently, the three criteria "local community", "society" and "workers" are considered in constructing the social assessment model, including a total of 18 applicable subcriteria. The local community category covers the cultural aspects of a local community (cultural heritage, delocalization and migration and respect of indigenous rights), its access to immaterial and material resources and to work (access to immaterial resources, access to material resources and local employment) and its social conditions (community engagement, safe and healthy living conditions and secure living conditions). The "society" category considers corruption and the prevention and mitigation of armed conflicts. The "worker" category addresses worker rights (equal opportunities/discrimination, freedom of association and collective bargaining), working conditions (working hours, fair salaries, health and safety) and the risk of involuntary labor (forced labor and child labor). Table 2 summarizes the results from the social dimension indicator selection process.

\section{Results}

In the following a case study of the assessment model for decision support within a raw material selection process (third question). Subsequently, a sensitivity analysis for selected indicators and corresponding weightings is carried out (fourth question).

\subsection{Case study for capacitor selection}

This section focuses on supporting decision problems in a corporate context. For this, the visualization of the assessment results increases the transparency and the level of understanding of the decision-making process (Finkbeiner et al., 2010; Traverso et al., 2012). The case study considers the process of selecting one of three different capacitor technologies: (i) aluminum-based, (ii) niobium-based and (iii) tantalum-based. Since each capacitor type contains only one major raw material, the results from the assessment model will help in a direct way to increase the sustainability level of a company. Therefore, the assessment has been performed for the three raw materials aluminum, tantalum and niobium, as shown in Fig. 2. Whenever data sources give scores on a country level, the share of global production determines the weighting of each country to the indicator score. Transforming indicator scales is necessary because of different units and of the need to aggregate the figures derived. All indicator scores are put on a dimensionless scale from 0 (non-critical) to 100 (highly critical). Data sources for the indicator assessment as well as the indicator transformation used are presented in the supplementary material. Technical criteria, such as capacity, 
operating temperature or size require a detailed technical understanding and must be considered by every company individually with respect to the intended application. Therefore, the present article does not focus on these aspects.

The small and medium-sized enterprise (SME) from the case study assembles small electronic components, such as capacitors or resistors, for individually fabricated circuit boards, as ordered by different clients. The SME has limited flexibility in choosing electronic components (i.e., the type of capacitor) and has to guarantee consistent composition, sometimes for up to twenty years. Securing the supply of the selected components is therefore vital. For instance, a problem with raw material-based supply shortages arose in the electronics industry in year 2010 when discussions about conflict minerals led to legislative changes ( Dodd-Frank Act, Section 1502) in the United States (United States Congress, 2010). This resulted in stricter due diligence regulations for the use of tantalum ores from the Democratic Republic of the Congo, including neighboring countries. At this time, global tantalum production was already strongly concentrated in this region (U.S. Geological Survey, 2012). The case study therefore focuses on how the SME can handle the tantalum capacitor, in view of raw material-based supply risk, environmental impacts and social implication. The other metals contained, such as copper, iron or nickel are always expected in electronic components. The focus for the raw material assessment thus lies on the "divergent" capacitor raw materials: tantalum, aluminum and niobium. The aggregation of supply risk scores of multiple raw materials to a technology level are discussed in detail in case studies for thin-film photovoltaics (Helbig et al., 2016a) and lithium-ion batteries ( Helbig et al., 2018 ).

Fig. 3 shows the results for the assessment of the three raw materials across all three assessment dimensions. Indicators with corresponding scores are shown in the outermost circle and aggregated scores in the center. Sector widths illustrate the individual weightings (see Fig. 2).

All the indicators included in the supply risk assessment are fully quantifiable without there being any data gaps. The assessment for aluminum with respect to the indicators "policy perception" (PP), "static reach reserves" (SRRV) and "static reach resources" (SRRS) is based on bauxite mining data. If the capacitor selection were to be made solely on the basis of the supply risk assessment, the aluminum capacitor would be the first choice. This is mainly because it has the lowest market concentration and the highest "recycling rate" (RR). Moreover, aluminum is not considered important for future technologies (FDT), and bauxite is a main mining product (CMF). Niobium shows a high market concentration, whereas the "demand increase risk" is low, similar to that for aluminum. Although tantalum scores best for political risk, its great importance for future technologies (FDT), high "companion metal fraction" (CMF) and low "recycling rate" (RR) lead to the highest supply risk among the three metals.

For the environmental dimension, the most comprehensive LCI database, ecoinvent, provided suitable data for aluminum and tantalum (ecoinvent Centre, 2010). Information on the environmental impacts of niobium was obtained from Nuss et al. (2014). A comparison of the three raw materials shows the least critical score per functional unit for aluminum, followed by niobium and tantalum. However, all scores indicate a low degree of criticality.

Niobium is found to be the least critical material concerning the social dimension, with most scores being non-critical, except those for "health and safety" (H\&S). Comparing aluminum and tantalum with one another, both show very similar results, so differences may only appear on sub-criteria level. Tantalum is most critical with regard to the indicators "cultural heritage" $(\mathrm{CH})$ and "child labor" (CL), whereas aluminum is considered most critical in the cases "forced labor" (FL) and "working hours" (WH). A more detailed analysis of the social indicators is therefore recommended to analyze social hotspots. Fig. 4 shows the assessment of the producing countries with respect to the 18 social indicators. The width of a cuboid (the country axis in Fig. 4) represents the country share of global production of the raw material, whereas the depth of a cuboid (the sub-criteria axis in Fig. 4) represents the weighting of the indicator (see Fig. 2). Its height and color code both illustrate the corresponding criticality score. For niobium, the overall noncritical score results from the good social assessment of the two main producing countries Brazil and Canada (U.S. Geological Survey, 2016). On the contrary, the aluminum assessment is highly diversified, with many "non-critical" scores for countries such as Australia or Norway, but also with many countries like China or Russia that score quite high. For tantalum, the social hotspot analysis shows alarming results. Although the aggregated scores (see Fig. 3) are similar to those for aluminum (due to the main producing country, Rwanda), high social risks emerge from the tantalum mined in the Democratic Republic of the Congo. Several sub-criteria, such as "safe and healthy living conditions" (S\&HLC), "child labor" (CL) or the "prevention and mitigation of armed conflicts" (PMAC), are found to be the most critical. Overall, when a substitute for the tantalum capacitor has to be found, both aluminum- and niobium-based capacitors can be recommended. Deciding between aluminum and niobium is possible on the basis of individual assessments in the three independent assessment dimensions. However, improvement of the tantalum procurement process by sourcing tantalum from socially stable countries, such as Brazil or Australia, can also be recommended, if feasible for the SME.

\subsection{Sensitivity analysis for selected indicators and indicator weightings}

A sensitivity analysis of the results is carried out using alternative indicator weightings and indicator selections, following a similar approach as previously applied to the assessment of supply risks associated with thin-film photovoltaic technologies (Helbig et al., 2016a). Most criticality assessments use an equal weighting of indicators or criteria (Achzet and Helbig, 2013), but different indicator weightings can lead to significantly different results (Erdmann and Graedel, 2011). For the assessment of supply risks and social implications for the three capacitor technologies (Al-, $\mathrm{Nb}$ - and Ta-based), the sensitivity of the base case (a) (see section 4.1 and Fig. 3) to two alternative weightings (b-c) and three alternative selections of indicators (d-f) is calculated and displayed in Fig. 5. Due to the integrated weighting of the ReCiPe method for the environmental impact assessment, a sensitivity analysis is not carried out for that dimension.

In the two alternative weightings the AHP process is left out: In (b), all indicators within an assessment dimension are weighted equally (9.09\% per indicator in the supply risk dimension, and $5.56 \%$ per indicator in the social dimension) and in (c) all criteria within an assessment dimension are weighted equally (25\% per criteria in the supply risk dimension with equal weighting of corresponding indicators, and $33.33 \%$ per criteria in the social dimension with equal weighting of corresponding indicators). The three alternative indicator selections ( $d-f$ ) preserve the pairwise comparisons for indicators and criteria from the AHP: in (d), the three indicators for both supply risk and social implications with the lowest weightings are removed, essentially reducing the indicator set; in (e), all indicators with weightings below average are removed; in (f), only the indicator with the highest weighting in each criterion is considered. An overview of the remaining indicators and their 


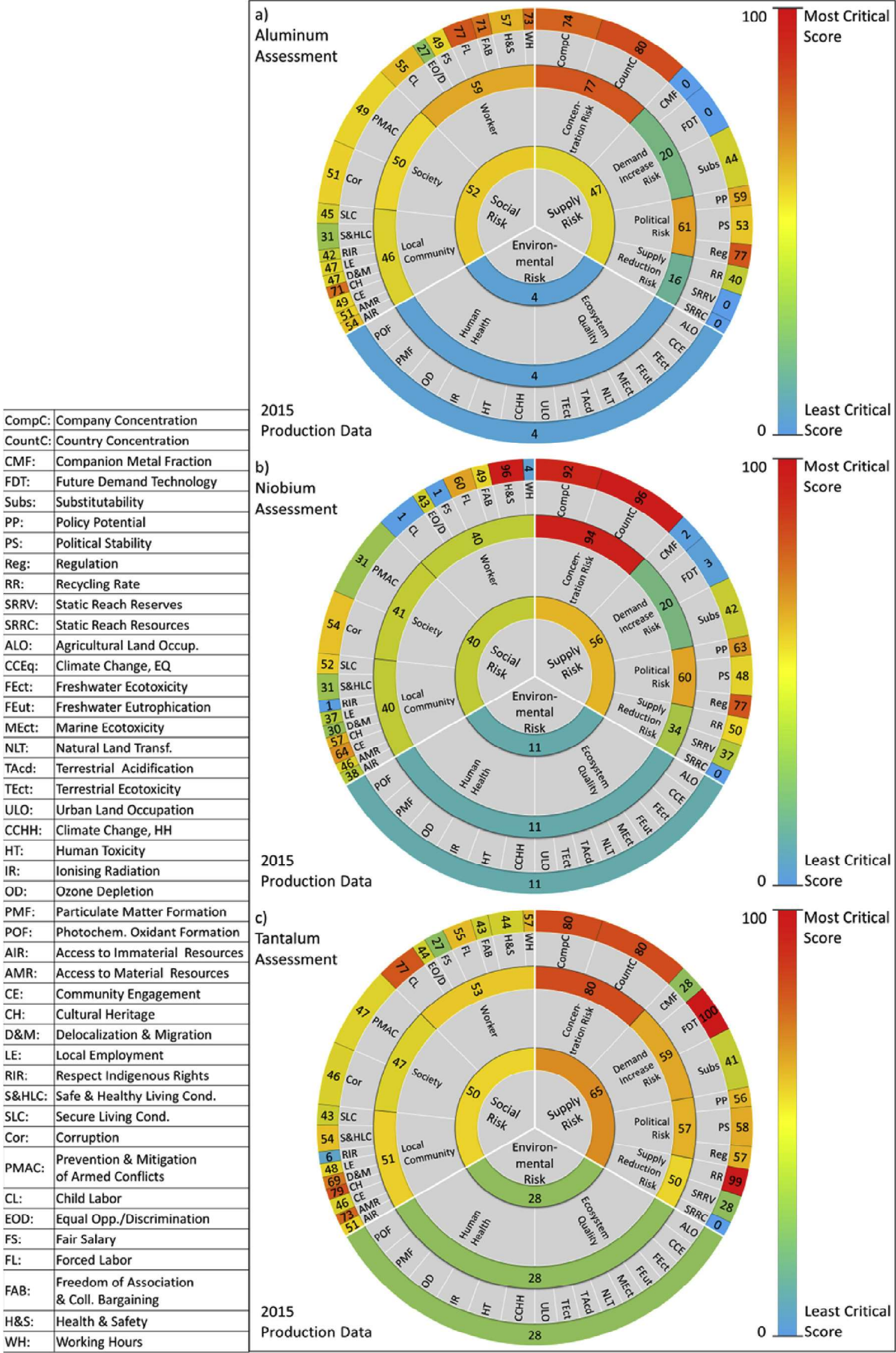

Fig. 3. Assessment for (a) aluminum, (b) niobium and (c) tantalum. 


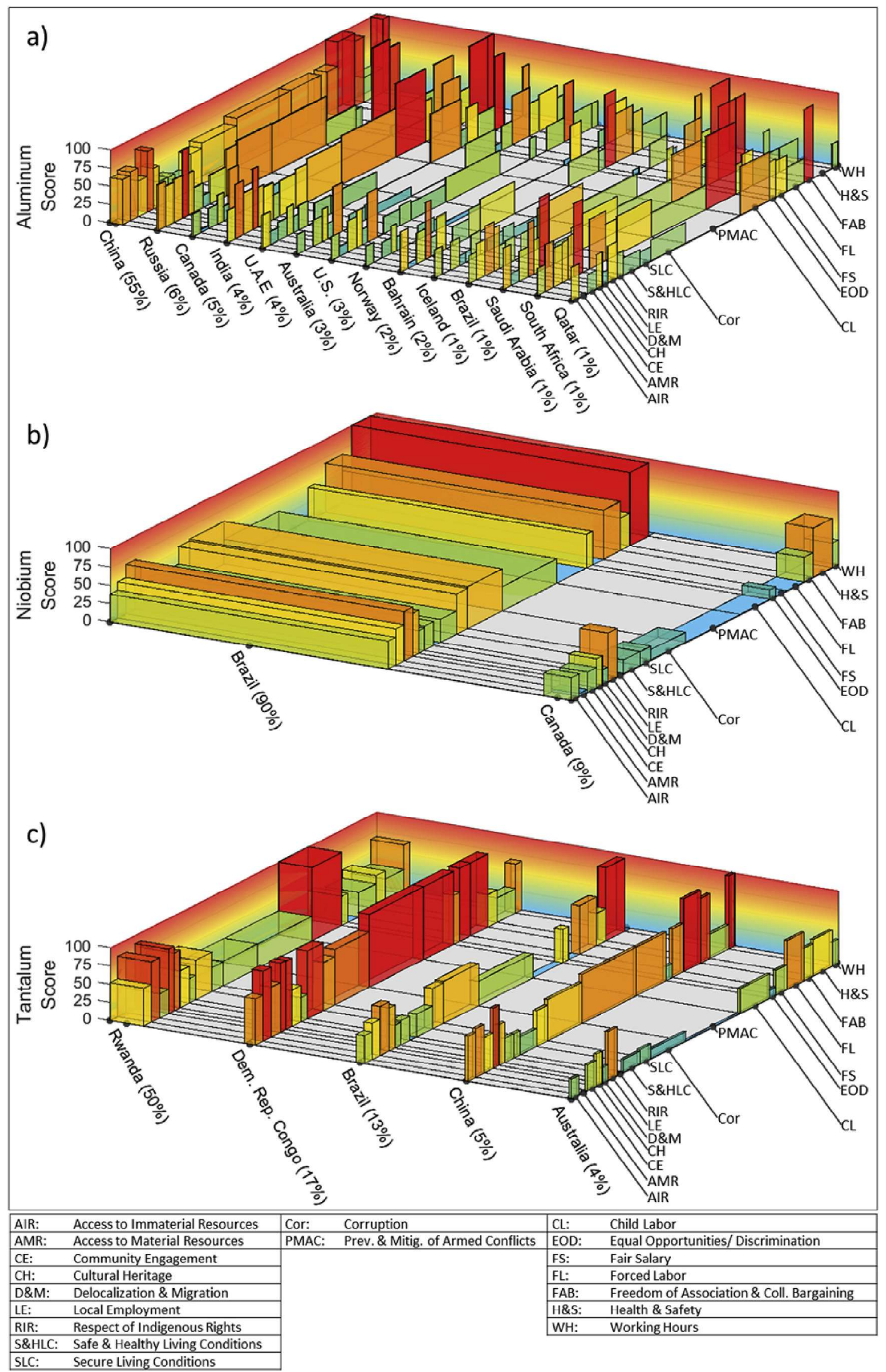

Fig. 4. Social dimension of the assessment per producing country for (a) aluminum, (b) niobium and (c) tantalum. 

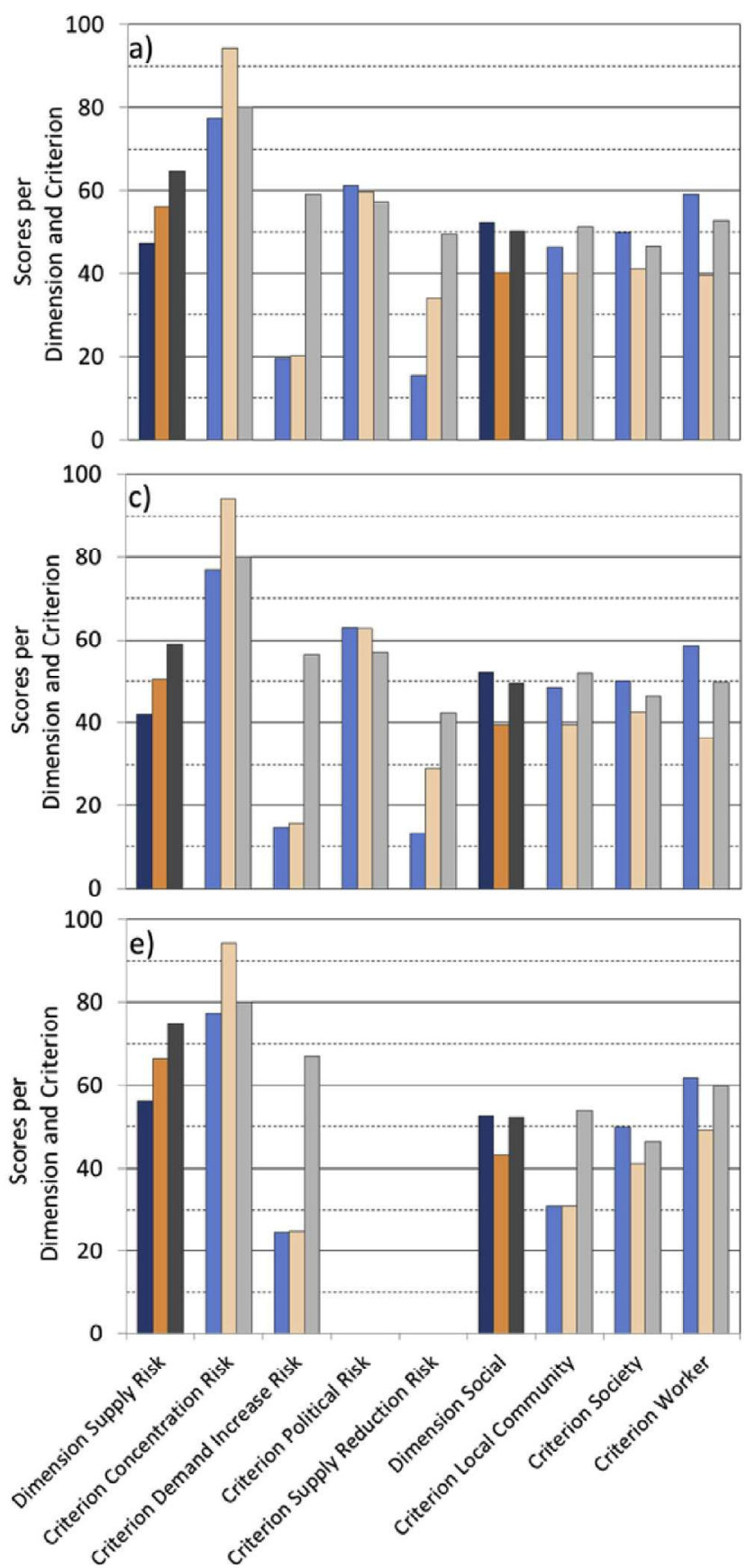
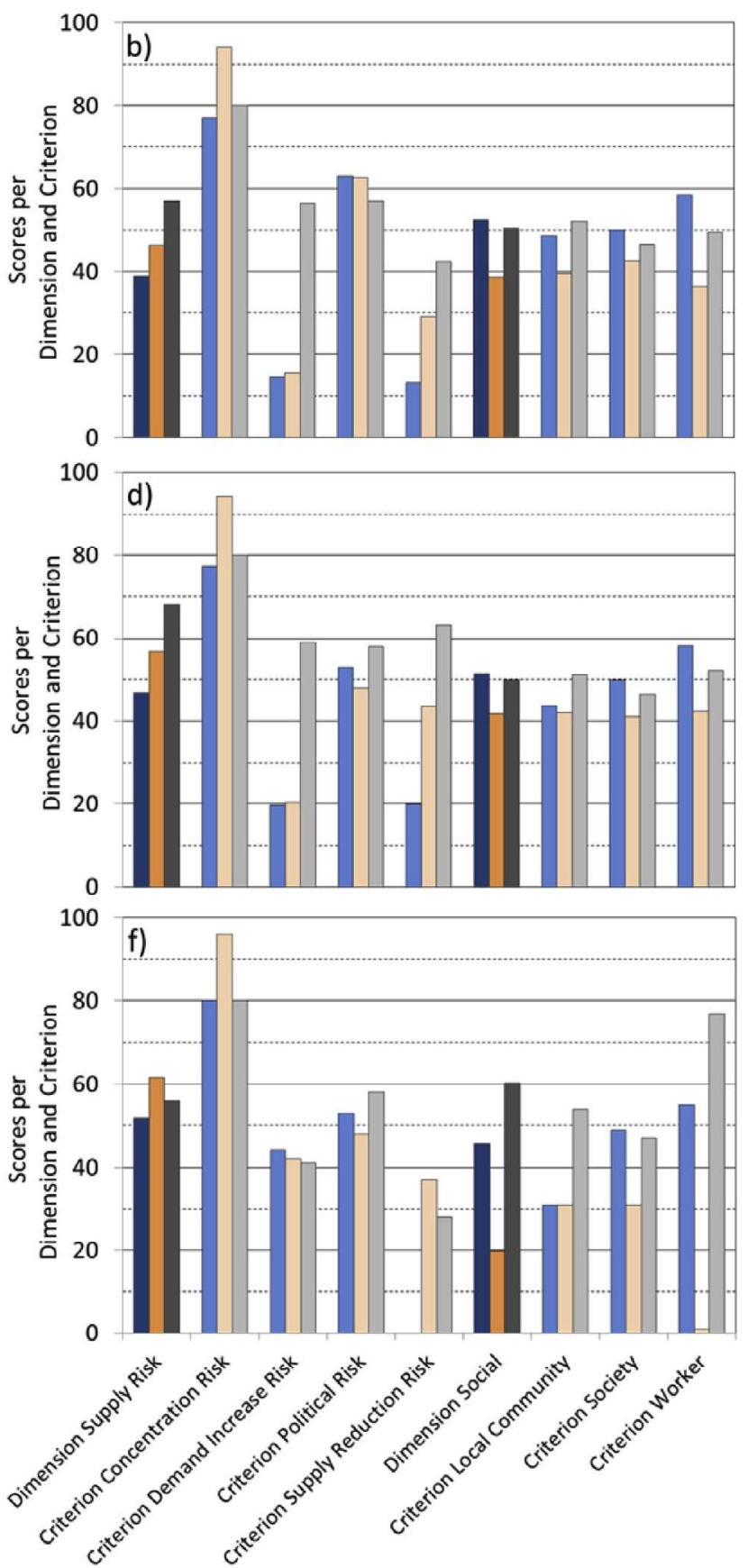
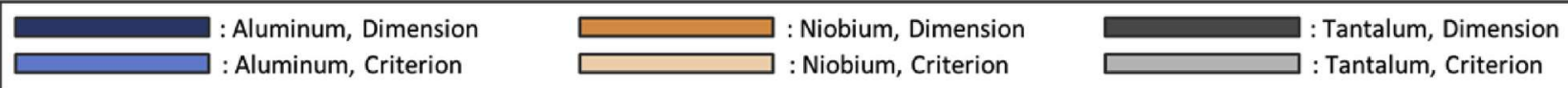

Fig. 5. Sensitivity analysis for the aggregated results of the aluminum, niobium and tantalum assessment. a) regular results (Section 4.1 and Fig. 3 ). b) equally weighted indicators within an assessment dimension. c) equally weighted criteria within an assessment dimension. d) three lowest weighted indicators for both supply risk and social implications are removed. e) indicators with weightings below average are removed. f) only indicator with the highest weighting in each criterion is considered.

corresponding weighting for each sensitivity analysis can be found in the supplementary material.

With the exception of the "maximum weighting indicator" case (f), the raw material preferences are uniform throughout the sensitivity analysis: the order of the individual values does not change. Both weighting variations (b, c) show an overall reduction of supply risk scores: Across all three calculation variations (AHP, equal indicator weighting, equal criteria weighting) the final aluminum supply risk score is reduced from 47 (a) to 39 (b) or 42 (c), the niobium supply risk score from 56 (a) to 46 (b) or 50 (c) and tantalum from 65 (a) to 57 (b) or 59 (c). This is due to the high importance attached to the concentration risk criterion and its corresponding indicators. Both weighting variations show little effect on the social dimension. Within the weighting variations (AHP, equal indicator weighting, equal criteria weighting) the final aluminum social score varies between 52 and 53, the niobium 
social dimension score varies between 39 and 40 and tantalum between 49 and 51. In all three weightings niobium has the best score, with the results for aluminum and niobium being worse and very similar to each other. The minor difference results from the social dimension containing 18 individual indicators, so that the effect of single indicator weighting variations is rather negligible. A country-level assessment (similar to Fig. 4) would be recommended in this case. An equal weighting of all social indicators would make the Democratic Republic of the Congo as a tantalum producing country look less critical, because most critical boxes would narrow their width and the less critical ones would increase in in width.

The effect of removing indicators from the assessment is more drastic, in particular for the last two sensitivity analyses (e, f). Limiting the supply risk assessment to the most important indicator of each criterion ( $f$ ) leads to the only change in the order of the raw material supply risk scores: Aluminum still has the best score with 52, but tantalum (56) has a less critical score than niobium (62). Additionally, when only the most important supply risk indicators are considered (e), the overall score for all three metals increases significantly. Not surprisingly, this effect is the opposite of the equal weighting sensitivity assessment, but a noteworthy consequence of this sensitivity analysis is the complete removal of the criteria "political risk" and "supply reduction risk". The effects of leaving out only the three least weighted indicators are negligible. The social implications show minor changes for two of the alternative indicator selections (d) and (e). However, limiting the assessment to the most strongly weighted indicator for each criterion (f) drastically increases the separation between the three elements: while niobium gets much better scores (20), tantalum (60) scores significantly higher and surpasses (in a negative sense) aluminum (46) in the social implications assessment. Overall, the sensitivity analyses show that the final scores are sensitive to weighting changes and indicator selections, but the resulting preferences for the substitution of tantalum-based capacitors by aluminum-based or niobium-based ones are robust. The latter is not necessarily the case when the assessments are limited to a single indicator in each criterion.

\section{Discussion}

We are of the opinion that the raw material assessment model presented in this paper fulfills the many requirements for application in the corporate context. The indicators used in all three sustainability dimensions are relevant and readily applicable for companies; their application is weighted via the AHP procedure (except for the environmental dimension) and a separate assessment of the social dimension (first and second questions above) is performed. The assessment evaluates (semi-)quantitatively the valuable information that a corporate decision-maker can make use of in addition to common supply chain risks such as those connected with transportation, purchasing or sub-suppliers (Stindt, 2017). Additional raw material information can help to make selections concerning different products, countries, or suppliers, but might stand in conflict with material efficiency aspects. For example, the permittivity of tantalum is approximately three times the permittivity of aluminum; tantalum capacitors with equal power will therefore need less material.

The assessment is strengthened by allowing considerations of real supply chains and differentiating between sourcing countries, as illustrated in the analysis conducted for the social dimension (see Fig. 4). In this connection, the graphical representation developed is helpful, since both individual indicator performances as well as aggregated indicator scores are readily understandable. The application of this assessment is expected to allow better decision support for companies in their selection of raw materials due to greater transparency and more specific data (third question above). The case study of an SME with three capacitor technologies demonstrated that this assessment enables an informed decision to be taken based on supply risk, environmental and social criteria. Several other case study applications are conceivable: in addition to electronic components such as microchips, or even smaller parts, such as resistors, the assessment model can be utilized to identify the least "critical" configuration of a product. The results from the sensitivity analysis substantiate the robustness of the assessment. However, the results for a raw material itself can vary largely depending on the specific indicator weightings and selection (fourth question above), as shown in Fig. 5.

Various digital tools for material selection in product design have been used (Ramalhete et al., 2010). Their focus often lies on the specific physical or mechanical properties of a material needed to fulfill certain requirements (Ashby and Johnson, 2014). The assessment model developed here can be used to generate additional information. Compared to common outranking methods like ELECTRE (Roy, 1991) or PROMETHEE (Brans et al., 1986), it does not present relative results. Compared to LCA, the data availability enables the assessment for numerous different raw materials. Compared to SLCA, the results of the assessment are quantitative. All of these properties could be advantageous for corporate decision-makers.

Finally, compared to other criticality assessments, the present model considers all three sustainability dimensions and carries out a structured indicator selection process with individual indicator weightings. It also delivers information for a hotspotanalysis, but does not evaluate specific individual raw material supply chains. Assessing a raw material based only on the performance of the producing countries means that different raw materials from the same country are evaluated on the same basis, without taking specific mining situations or extraction techniques into account. Consequently, results from the present assessment model are to be considered as giving a valuable first insight. When comparing the results of the assessments to results from other authors in the literature (for instance British Geological Survey (BGS), 2012; Graedel et al., 2015b; Pfleger et al., 2015), several similarities are observable on the highest aggregated supply risk level. Although it must be taken into account that every study uses a different set of indicators, aluminum normally achieves a similar score (around 50 on a scale from 0 to 100 with 100 being the most critical score). It also has the lowest score compared to niobium and tantalum. Niobium and tantalum often score very close, with sometimes one, sometimes the other, showing the highest criticality score. More detailed information is presented in the supplementary material. The strength of the assessment model developed in this article is to allow a decision-maker to understand how final scores are derived from single indicator performances. Comparing the results from the environmental and social dimension to other assessment results from the literature is not possible, as no data from one study are available for at least two of the raw materials considered here.

Looking closer at the assessment results themselves (see Fig. 3), differences in the environmental dimension compared to the supply risk and social dimension are apparent, since no individual indicator scores are calculated for the environmental dimension due to the ReCiPe method used. The relevant raw data from the ecoinvent database or from the literature are therefore presented in the supplementary material. The extremely low score for aluminum can be explained by the fact that every indicator gives rise to a very low midpoint score. In comparison, the highest score for tantalum results mainly from the indicator "climate change". The highest supply risk is associated with tantalum, mainly due to 
its high company and country concentration, the expected demand for future technologies and the low recycling rate (see Fig. 3). Additionally, several producing countries are "critical" in the sense of the accompanying social aspects, such as in the Democratic Republic of the Congo (see Fig. 4). Comparing tantalum and niobium, the assessment model gives a lower total risk for niobium. Although niobium has the highest concentration risk, other criteria lower the supply risk level compared to tantalum (see Fig. 3). This is supported by the good assessment in social aspects of the two main producing countries Brazil and Canada (see Fig. 4).

The many criteria in all three assessment dimensions may lead to intermediate results, which are important for the expert, but may be difficult to interpret on the executive level in a company. The necessary aggregation can lead to ethical problems of weighing up different impact areas against each other, especially in the social dimension. Some sub-criteria within the social dimension, such as child labor and working hours, deserve a more detailed discussion (Arvidsson et al., 2015). The method is further limited by the accuracy and resolution of the collected data in step 1.1 and 1.2 of the guideline (see Fig. 1). This sometimes comes into play when the knowledge of the raw material content of a product is limited to the company itself. Some companies, especially SMEs, do not even know all the raw materials contained in their products and thus the supply chains on which they depend (Kyngdon-McKay et al., 2015). In the subsequent raw material assessment, despite regional data being rarely available, reporting on the regional level would sometimes be useful, rather than reporting only on the country level (e.g., to indicate the share of primary materials produced in the conflict zone of the eastern part of the Democratic Republic of the Congo).

\section{Conclusion}

The assessment model presented in this article can be of major benefit to companies, as it explicitly covers supply risks, environmental impact and social implications. Moreover, it uses indicators that are both relevant and applicable from a company perspective. The quantitative raw material assessment model results from literature analysis, best practice in companies, expert questionnaires and interdisciplinary workshops with participants from both industry and academia. Potential recommendations, such as the substitution possibilities for specific raw materials or technologies and the variation of raw material procurement, can be derived from the assessment results. The applicability of the model for decision support in raw material selection has been successfully demonstrated in the case of capacitor selection.

The effects of indicator weighting variations are substantial but not vital for the decision support. Here, assessing additional raw materials would be helpful to understand better the effect of indicator weighting variation. Testing different indicator sets with weighting scenarios for numerous raw materials could further improve the structured criticality assessment methodology. So far it has been difficult to determine which of the available assessment models is most advantageous for assessing raw materials on the company-level.

For the routine application and integration of the assessment model developed here into the daily business of a commercial organization, indicator data for various raw materials could be prepared by experts from academia and used to form the basis of an environmental management information system (EMIS). However, simply understanding and interpreting the assessment results can still be challenging without expert support.

In further research we will attempt to create a database with datasets for several different raw materials including historical data. As a part of this exercise, we will further validate our results for more raw materials. In this connection, further discussion of the structure, indicator selection and indicator weighting of the assessment model presented here for other raw materials seems promising. Clearly, the application of the assessment model to more case studies would be particularly useful for further research. The correlation of criticality-based raw material assessments with other supply chain risk assessments could be analyzed, in order to develop a stronger connection between the two research fields, which can be beneficial for both sides.

\section{Acknowledgements}

This study was carried out by the support of the German Environmental Foundation (DBU). We further thank Prof. Dr. Bernd Wagner for his counselling in the advisory board of the DBU project. The DBU project was also supported by the Bavarian graduate school "Resource strategy concepts for sustainable energy systems" of the Institute of Materials Resource Management (MRM) of the University of Augsburg. This article is a further development and continuation of the results presented in (Tuma et al., 2014). We further thank all our colleagues who answered the questionnaires. We are also grateful to A.M. Bradshaw for very helpful discussions.

\section{Appendix A. Supplementary data}

Supplementary data related to this article can be found at https://doi.org/10.1016/j.jclepro.2017.12.162.

\section{References}

Achzet, B., Helbig, C., 2013. How to evaluate raw material supply risks - an overview. Resour. Pol. 38, 435-447.

Ahi, P., Searcy, C., 2013. A comparative literature analysis of definitions for green and sustainable supply chain management. J. Clean. Prod. 52, 329-341.

Arvidsson, R., Kushnir, D., Molander, S., Sandén, B.A., 2015. Energy and resource use assessment of graphene as a substitute for indium tin oxide in transparent electrodes. J. Clean. Prod. 132, 289-297.

Ashby, M.F., Johnson, K., 2014. Materials and Design. The Art and Science of Materia Selection in Product Design. Previous edition: 2009. Butterworth-Heinemann, Amsterdam. http://www.sciencedirect.com/science/book/9780080982052.

Bach, V., Berger, M., Henßler, M., Kirchner, M., Leiser, S., Mohr, L., Rother, E. Ruhland, K., Schneider, L., Tikana, L., Volkhausen, W., Walachowicz, F., Finkbeiner, M., 2016. Integrated method to assess resource efficiency - ESSENZ. J. Clean. Prod. 137, 118-130.

Benoît, C., Norris, G.A., Valdivia, S., Ciroth, A., Moberg, A., Bos, U., Prakash, S. Ugaya, C., Beck, T., 2010. The guidelines for social life cycle assessment of products: just in time! Int. J. Life Cycle Assess. 15, 156-163.

Benoît Norris, C., 2014. Data for social LCA. Int. J. Life Cycle Assess. 19, 261-265.

Benoit-Norris, C., Cavan, D.A., Norris, G., 2012. Identifying social impacts in product supply chains: overview and application of the social hotspot database. Sustainability 4, 1946-1965

Brans, J.P., Vincke, P., Mareschal, B., 1986. How to select and how to rank projects. The Promethee method. Eur. J. Oper. Res. 24, 228-238.

British Geological Survey (BGS), 2012. Risk List 2012. http://www.bgs.ac.uk/minera lsuk/statistics/risklist.html.

Buchholz, P., 2014. Angebotskonzentration bei mineralischen Rohstoffen und Zwischenprodukten - potenzielle Preis- und Lieferrisiken. DERA-Rohstoffliste 2012 DERA, Hannover.

Carter, C.R., Rogers, D.S., 2008. A framework of sustainable supply chain management. Moving toward new theory. Int Jnl Phys Dist \& Log Manag. 38, 360-387.

Consult, I.W., 2011. Rohstoffsituation Bayern: Keine Zukunft ohne Rohstoffe. Strategien und Handlungsoptionen. http://www.rohstoffstrategie-bayern.de/file dmin/user_upload/rohstoffstrategie/dokumente/vbw_Rohstoffsituation_Baye rn_keine_Zukunft_ohne_Rohstoffe.pdf.

Crum, M., Carter, C.R., Liane Easton, P., 2011. Sustainable supply chain management Evolution and future directions. Int Jnl Phys Dist \& Log Manag. 41, 46-62.

Curran, M.A., 2012. Life Cycle Assessment Handbook. A Guide for Environmentally Sustainable Products. Wiley, Hoboken, NJ. https://doi.org/10.1002/ 9781118528372

Dekker, R., Bloemhof, J., Mallidis, I., 2012. Operations Research for green logistics an overview of aspects, issues, contributions and challenges. Eur. J. Oper. Res. 219, 671-679.

Diakoulaki, D., Mavrotas, G., Papayannakis, L., 1995. Determining objective weights in multiple criteria problems. The critic method. Comput. Oper. Res. 22, 763-770. 
Dodd-Frank Wall Street Reform and Consumer Protection Act, 2010. Public Law $111-203$.

Dreyer, L., Hauschild, M., Schierbeck, J., 2006. A framework for social life cycle impact assessment. Int. J. Life Cycle Assess. 11, 88-97.

Duclos, S.J., Otto, J.P., Konitzer, D.G., 2008. Design in an era of constrained resources. As global copetition for material strains the supply chain, companies must know where a shortage can hurt and then plan around it. Mechanic. Eng. Magazi. 132, 36-40.

ecoinvent Centre, 2010. Ecoinvent Data v2.2. The 2010 Version of the Most Comprehensive and Most Popular Public LCI Database. Dübendorf.

Ekener-Petersen, E., Finnveden, G., 2013. Potential hotspots identified by social LCA - part 1: a case study of a laptop computer. Int. J. Life Cycle Assess. 18, $127-143$.

Elkington, J., 1999. In: Cannibals with Forks. The Triple Bottom Line of 21st Century Business, Paperback. publ. Capstone Publ, Oxford.

Erdmann, L., Graedel, T.E., 2011. Criticality of non-fuel minerals: a review of major approaches and analyses. Environ. Sci. Technol. 45, 7620-7630.

European Commission, 2010. Critical Raw Materials for the EU. Report of the Ad-hoc Working Group on Defining Critical Raw Materials. Brüssel. http://ec.euro pa.eu/enterprise/policies/raw-materials/critical/index_en.htm.

European Commission, 2011. International Reference Life Cycle Data System (ILCD) Handbook - Recommendations for Life Cycle Impact Assessment in the European Context. - Based on Existing Environmental Impact Assessment Models and Factors. Publications Office of the European, Luxemburg.

European Commission, 2014. Critical Raw Materials for the EU. Report of the Ad-hoc Working Group on Defining Critical Raw Materials. Brüssel. http://ec.euro pa.eu/enterprise/policies/raw-materials/files/docs/crm-report-on-critical-rawmaterials_en.pdf.

Figueira, J., Roy, B., 2002. Determining the weights of criteria in the ELECTRE type methods with a revised Simos' procedure. Eur. J. Oper. Res. 139, 317-326.

Finkbeiner, M., Schau, E.M., Lehmann, A., Traverso, M., 2010. Towards life cycle sustainability assessment. Sustainability 2, 3309-3322.

Finnveden, G., Hauschild, M.Z., Ekvall, T., Guinée, J., Heijungs, R., Hellweg, S., Koehler, A., Pennington, D., Suh, S., 2009. Recent developments in life cycle assessment. J. Environ. Manag. 91, 1-21.

Fridgen, G.S., König, C., Mette, P., Rathgeber, A.W., 2013. Die Absicherung von Rohstoffrisiken - eine Disziplinen übergreifende Herausforderung für Unternehmen. Schmalenbachs Z. für Betriebswirtschaftliche Forsch. 167-190.

Glöser, S., Tercero Espinoza, L., Gandenberger, C., Faulstich, M., 2015. Raw material criticality in the context of classical risk assessment. Resour. Pol. 44, 35-46.

Goedkoop, M., Heijungs, R., Huijbregts, M., Schryver, A. de, Struijs, J., Zelm, R. 2013. ReCiPe 2008. A Life Cycle Impact Assessment Method Which Comprises Harmonised Category Indicators at the Midpoint and the Endpoint Level, first ed. (revised), Report I: Characterisation.

Govindan, K., Rajendran, S., Sarkis, J., Murugesan, P., 2015. Multi criteria decision making approaches for green supplier evaluation and selection. A literature review. J. Clean. Prod. 98, 66-83.

Graedel, T.E., Reck, B.K., 2016. Six years of criticality assessments: what have we learned so far? J. Ind. Ecol. 20 (4), 692-699.

Graedel, T.E., Barr, R. Chandler, C. Chase, T. Choi, J., Christoffersen, L. Friedlander, E., Henly, C., Jun, C., Nassar, N.T., Schechner, D., Warren, S., Yang, M., Zhu, C., 2012. Methodology of metal criticality determination. Environ. Sci. Technol. 46, 1063-1070.

Graedel, T.E., Harper, E.M., Nassar, N.T., Reck, B.K., 2015a. On the materials basis of modern society. Proc. Natl. Acad. Sci. Unit. States Am. 112, 6295-6300.

Graedel, T.E., Harper, E.M., Nassar, N.T., Nuss, P., Reck, B.K., 2015b. Criticality of metals and metalloids. Proc. Natl. Acad. Sci. Unit. States Am. 112, 4257-4262.

Guinée, J.B., Heijungs, R., Huppes, G., Zamagni, A., Masoni, P., Buonamici, R., Ekvall, T., Rydberg, T., 2011. Life cycle assessment: past, present, and future. Environ. Sci. Technol. 45, 90-96.

Harper, E.M., Diao, Z., Panousi, S., Nuss, P., Eckelman, M.J., Graedel, T.E., 2015a. The criticality of four nuclear energy metals. Resour. Conserv. Recycl. 95, 193-201.

Harper, E.M., Kavlak, G., Burmeister, L., Eckelman, M.J., Erbis, S., Sebastian Espinoza, V., Nuss, P., Graedel, T.E., 2015b. Criticality of the geological zinc, tin, and lead family. J. Ind. Ecol. 19, 628-644.

Helbig, C., Bradshaw, A.M., Kolotzek, C., Thorenz, A., Tuma, A., 2016a. Supply risks associated with CdTe and CIGS thin-film photovoltaics. Appl. Energy 178, 422-433.

Helbig, C., Wietschel, L., Thorenz, A., Tuma, A., 2016b. How to evaluate raw material vulnerability - an overview. Resour. Pol. 48, 13-24.

Helbig, C., Bradshaw, A.M., Wietschel, L., Thorenz, A., Tuma, A., 2018. Supply risks associated with lithium-ion battery materials. J. Clean. Prod. 172, 274-286.

Henßler, M., Bach, V., Berger, M., Finkbeiner, M., Ruhland, K., 2016. Resource efficiency assessment-comparing a plug-in hybrid with a conventional combustion engine. Resources 5, 5 .

Hossaini, N., Reza, B., Akhtar, S., Sadiq, R., Hewage, K., 2014. AHP based life cycle sustainability assessment (LCSA) framework: a case study of six storey wood frame and concrete frame buildings in Vancouver. J. Environ. Plann. Manag. 58, 1217-1241.

Hosseinijou, S.A., Mansour, S., Shirazi, M.A., 2014. Social life cycle assessment for material selection: a case study of building materials. Int. J. Life Cycle Assess. 19, $620-645$.

Hsu, A.J., Emerson, M., Levy, A., Sherbinin, L.de, Johnson, O., Malik, J., Schwartz Jaiteh, M., 2014. The 2014 Environmental Performance Index. www.epi.yale.edu
Huy, Dieter, Andruleit, Harald, Babies, Hans-Georg, Homberg-Heumann, Doris, Meßner, Jürgen, Neumann, Wolfgang, Röhling, Simone, Schauer, Michael, Schmidt, Sandro, Schmitz, Martin, Sievers, Henrike, 2013. Deutschland - Rohstoffsituation 2012. Hannover.

Jørgensen, A., Le Bocq, A., Nazarkina, L., Hauschild, M., 2008. Methodologies for social life cycle assessment. Int. J. Life Cycle Assess. 13, 96-103.

Jørgensen, A., Hauschild, M.Z., Jørgensen, M.S., Wangel, A., 2009. Relevance and feasibility of social life cycle assessment from a company perspective. Int. J. Life Cycle Assess. 14, 204-214.

Jørgensen, A., Dreyer, L.C., Wangel, A., 2012. Addressing the effect of social life cycle assessments. Int. J. Life Cycle Assess. 17, 828-839.

Kruse, S.A., Flysjö, A., Kasperczyk, N., Scholz, A.J., 2009. Socioeconomic indicators as a complement to life cycle assessment-an application to salmon production systems. Int. J. Life Cycle Assess. 14, 8-18.

Kyngdon-McKay, Y., Jorns, A., Levin, E., Song, Y., 2015. Assessing and Enhancing the Contribution of Small and Medium-scale Assessing and Enhancing the Contribution of Small and Medium-scale Enterprises to Due Diligence for Responsible Mineral Supply Chains. http://www.bgr.bund.de/DE/Themen/Min_rohstoffe/Do Mineral Supply Chains. http://www.bgr.bund.de/DE/Themen/Min_rohstoffe/Do
wnloads/Assessing_enhancing_due_diligence_supply_chains.pdf?_blob=publi cationFile\& $\mathrm{V}=5$.

Lehmann, A., Zschieschang, E. Traverso, M., Finkbeiner, M. Schebek, L., 2013. Social aspects for sustainability assessment of technologies-challenges for social life cycle assessment (SLCA). Int. J. Life Cycle Assess. 18, 1581-1592.

Mason, L., Prior, T., Mudd, G., Giurco, D., 2011. Availability, addiction and alternatives: three criteria for assessing the impact of peak minerals on society. J. Clean. Prod. 19, 958-966.

Nassar, N.T., Barr, R., Browning, M., Diao, Z., Friedlander, E., Harper, E.M., Henly, C., Kavlak, G., Kwatra, S., Jun, C., Warren, S., Yang, M.-Y., Graedel, T.E., 2012. Criticality of the geological copper family. Environ. Sci. Technol. 46, 1071-1078.

Nassar, N.T., Du, X., Graedel, T.E., 2015. Criticality of the rare earth elements. J. Ind. Ecol. 19 (4), 1044-1054.

Norris, C., Norris, G., Aulisio, D., 2014. Efficient assessment of social hotspots in the supply chains of 100 product categories using the social hotspots database. Sustainability 6, 6973-6984.

Nuss, P., Harper, E.M., Nassar, N.T., Reck, B.K., Graedel, T.E., 2014. Criticality of iron and its principal alloying elements. Environ. Sci. Technol. 48, 4171-4177.

Pagell, M., Wu, Z., 2009. Building a more complete theory of Sustainable Supply Chain Management using case studies of 10 examplars. J. Supply Chain Manag. $45,37-56$.

Panousi, S., Harper, E.M., Nuss, P., Eckelman, M.J., Hakimian, A., Graedel, T.E., 2016. Criticality of seven specialty metals. J. Ind. Ecol. 20 (4), 837-853.

Parent, J., Cucuzzella, C., Revéret, J.-P., 2010. Impact assessment in SLCA: sorting the sLCIA methods according to their outcomes. Int. J. Life Cycle Assess. 15, 164-171.

Parent, J., Cucuzzella, C., Revéret, J.-P., 2013. Revisiting the role of LCA and SLCA in the transition towards sustainable production and consumption. Int. J. Life Cycle Assess. 18, 1642-1652.

Pfleger, P., Lichtblau, K., Bardt, H., Bertenrath, R., 2015. Rohstoffsituation der bayerischen Wirtschaft. https://www.rohstoffstrategie-bayern.de/fileadmin/use r_upload/rohstoffstrategie/dokumente/Update-Studie-Rohstoffsituation-der-ba yerischen-Wirtschaft-2015.pdf. Accessed November 152016

Pimentel, B.S., Gonzalez, E.S., Barbosa, G.N., 2016. Decision-support models for sustainable mining networks. Fundamentals and challenges. J. Clean. Prod. 112, 2145-2157.

Ramalhete, P.S., Senos, A., Aguiar, C., 2010. Digital tools for material selection in product design. Mater. Des.(1980-2015) 31, 2275-2287.

Roelich, K., Dawson, D.A., Purnell, P., Knoeri, C., Revell, R., Busch, J., Steinberger, J.K., 2014. Assessing the dynamic material criticality of infrastructure transitions: a case of low carbon electricity. Appl. Energy 123, 378-386.

Roy, B., 1991. The outranking approach and the foundations of electre methods. Theor. Decis. 31, 49-73.

Saaty, T.L., 1990. How to make a decision: the analytic hierarchy process. Eur. J. Oper. Res. 48, 9-26.

Saaty, T.L., Varga, L.G., 1994. Decision Making in Economic, Political, Social and Technological Environments with the Analytic Hierarchy Process. RWS Publ, Pittsburgh, Penn.

Sauer, P.C., Seuring, S., 2017. Sustainable supply chain management for minerals. J. Clean. Prod. 151, 235-249.

Seuring, S., 2013. A review of modeling approaches for sustainable supply chain management. Decis. Support Syst. 54, 1513-1520.

Seuring, S., Müller, M., 2008. Core issues in sustainable supply chain management a Delphi study. Bus. Strat. Environ. 17, 455-466.

Smith, J., Barling, D., 2014. Social impacts and life cycle assessment: proposals for methodological development for SMEs in the European food and drink sector. Int. J. Life Cycle Assess. 19, 944-949.

Stindt, D., 2017. A generic planning approach for sustainable supply chain management - how to integrate concepts and methods to address the issues of sustainability? J. Clean. Prod. 153, 146-163.

Traverso, M., Finkbeiner, M., Jørgensen, A., Schneider, L., 2012. Life cycle sustainability dashboard. J. Ind. Ecol. 16, 680-688.

Tuma, A., Reller, A., Thorenz, A., Kolotzek, C., Helbig, C., 2014. Nachhaltige Ressourcenstrategien in Unternehmen: Identifikation kritischer Rohstoffe und Erarbeitung von Handlungsempfehlungen zur Umsetzung einer ressourceneffizienten Produktion. Augsburg).

UNEP/SETAC, 2009. Guidelines for Social Life Cycle Assessment of Products. United Nations Environment Programme. United Nations Environment Programme, Paris. 
UNEP/SETAC, 2013. The Methodological Sheets for Subcategories in Social Life Cycle Assessment (S-LCA). http://www.lifecycleinitiative.org/wp-content/uploads 2013/11/S-LCA_methodological_sheets_11.11.13.pdf.

U.S. Geological Survey, 2012. Mineral Commodity Summaries. Tantalum. http://mi nerals.usgs.gov/minerals/pubs/commodity/niobium/mcs-2012-tanta.pdf.

U.S. Geological Survey, 2016. Mineral Commodity Summaries. Niobium. http://mine rals.usgs.gov/minerals/pubs/commodity/niobium/mcs-2016-niobi.pdf.

U.S. National Research Council, 2008. Minerals, Critical Minerals, and the U.S Economy. National Academies Press, Washington, D.C.

U.S. Department of Energy (DOE), 2011. Critical Materials Strategy. http://energy.go v/sites/prod/files/DOE_CMS2011_FINAL_Full.pdf.
Weidema, B.P., 2006. The integration of economic and social aspects in life cycle impact assessment. Int. J. Life Cycle Assess. 11, 89-96.

Wu, R., Yang, D., Chen, J., 2014. Social life cycle assessment revisited. Sustainability 6, 4200-4226.

Yeh, C.-H., Willis, J.R., Deng, H., Pan, H., 1999. Task oriented weighting in multicriteria analysis. Eur. J. Oper. Res, 119, 130-146.

Zorzini, M. Hendry, LC, Huq, FA Stevenson, M. 2015. Socially responsible sourcing. Reviewing the literature and its use of theory. Int. J. Op Prod. Manag. $35,60-109$. 